\title{
Back to the Future: The National Acupuncture Detoxification Association (NADA) Protocol Persists as an Agent of Social Justice and Community Healing by the People and for the People
}

\author{
Claudia Voyles ${ }^{1 *}$, Kenneth Carter $^{2}$ and Laura Cooley ${ }^{3}$ \\ ${ }^{1}$ Professor, AOMA Graduate School of Integrative Medicine, USA \\ ${ }^{2}$ NADA President, MD, MPH, Dipl. NCCAOM, USA \\ ${ }^{3} L A c, U S A$
}

*Corresponding author: Claudia Voyles, DAOM, LAc, Professor, AOMA Graduate School of Integrative Medicine, 4701 West Gate Blvd Austin, TX 78745, USA

\section{Opinion}

NADA arose from a community response to inequities. NADA calls on the acupuncture community to support such communitybased responses now. In the early 1970s, young activists in New York City agitated for change. Collectives comprised of many civicminded activist organizations led by the Puerto Rican Young Lords Party called out systematic racism and oppression including the effects of social injustice upon the health of the people of color in the South Bronx. The actions of the Young Lords Party, the Black Panther Party, White Lightning, and others addressed many healthrelated concerns: trash collection, lead and tuberculosis screening, food insecurity, incarceration conditions and addiction. The movement was political and focused on social justice.
The South Bronx city hospital, Lincoln, called "the butcher shop" by locals, was not responsive to the call for help with the rampant heroin epidemic. So, in late 1970, the "Think Lincoln Committee" launched a surprise takeover and protest occupation of the Nurses' Residence. Subsequent negotiations led to the creation of the Lincoln Detox Program, staffed with those same community members as well as progressive medical professionals. The program initially offered a short-term methadone detoxification intervention and had 200 people lined up on the first day. Until then, the only available treatment was forced methadone maintenance. The focus of Lincoln Detox was on social justice and the need for political education, engagement, and political healing in addition to individual health concerns (Figure $1 \& 2$ ).

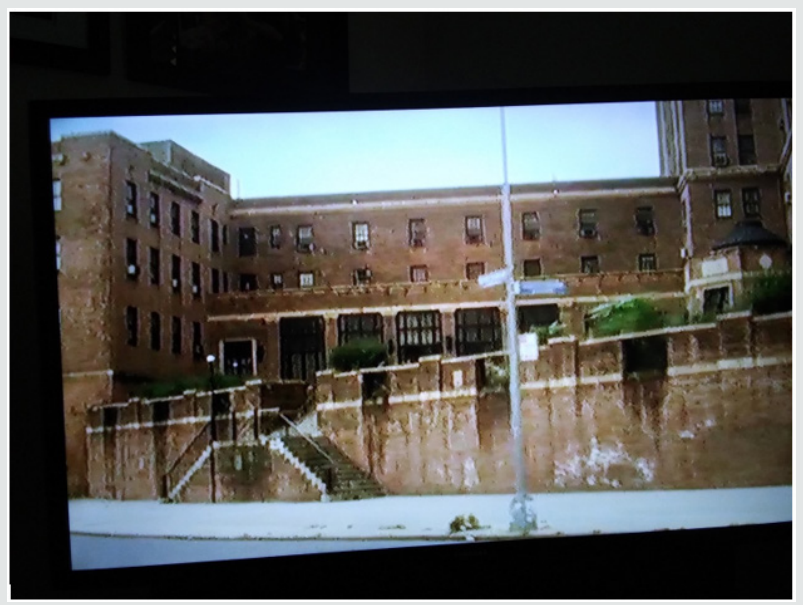

Figure 1. 


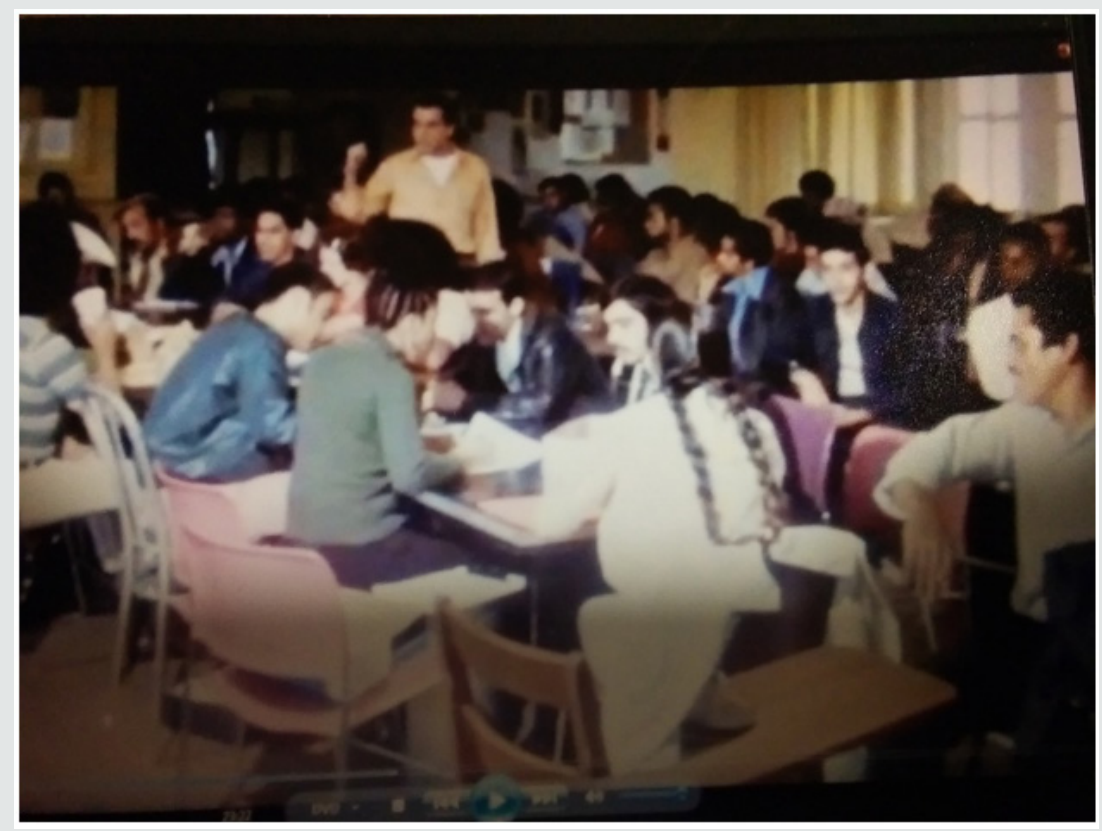

Figure 2.

Soon concerns about methadone as a chemical means of control and the challenges of methadone detoxification prompted the group to look for more Wholistic alternatives. Several activist staff members, including Mutulu Shakur and Walter Bosque Del Rio, went to Chinatown and hired an acupuncturist, who taught them to needle one ear point. Bosque Del Rio explained that the seminal Lincoln team, partially self-taught, pioneered the start of what is now known as the NADA protocol. The late Michael O. Smith completed the five-point combination in a collaborative effort of the treatment community and the persons getting care. Thousands of people were detoxed, and methadone was eventually dropped. The ear acupuncture success gained international attention. Over time, the NADA protocol has continued to undergo substantial refinement based on client feedback, staff observations and largevolume, wholistic clinical outcomes.

Several of the Lincoln members, including Smith, pursued further Traditional East Asian Medicine studies in Canada, China, and Shri Lanka, becoming full-body acupuncturists. Shakur along with Bosque Del Rio, Oscar Wexu and Mario Wexu, established an acupuncturist training program at Lincoln, one of, if not the first in the United States. Louis Surita (Zubair), Shakur and Bosque Del Rio "ran the Acupuncture Collective, the clinic and the Lincoln Acupuncture School from 1972-1978," recalled Bosque Del Rio. After leaving Lincoln, Shakur created the Black Acupuncture Advisory Association of North America (BAAANA) and the Harlem Institute of Acupuncture. Bosque Del Rio became the Assistant Director of the Tri-State Acupuncture Institute and later served on the board of Tri-State College of Acupuncture.

Bosque Del Rio relayed that the city eventually took over, transferring the activists to other methadone programs that were not using acupuncture or political education. Lincoln Detox continued, without the militant political orientation, to provide ear acupuncture-based treatment, under Smith's leadership. As cofounder of the NADA organization and ongoing Medical Director of what became Lincoln Recovery Center Smith kept the movement alive and facilitated broad adoption.

Carlos Alvarez became the primary NADA trainer sharing the NADA ear acupuncture and style of treatment. Nancy Smalls designed a ground-breaking maternal program with comprehensive services including peer counselors. Alvarez pointed out that over time more and more social workers and counselors, as well as acupuncturists, came and learned the Lincoln style of treatment, taking it back and applying it to their own communities. Alvarez noted, "We went through a series of epidemics: heroin, crack/ cocaine, AIDS, Hepatitis C, 1970s - 80s - 90s and on, with acudetox and supportive services."

Honoring these roots, NADA has always focused on the underserved and marginalized. The "Spirit of NADA" is service. The NADA protocol-a style of engagement and care that includes a simple ear combination, often delivered in groups-works well not only for addiction and mental health conditions, but also in disaster response and emotional trauma healing, fostering dignity, hope and resiliency. NADA practitioners, including non-acupuncturists from various disciplines, continue to bring support to people in behavioral health, criminal justice, community initiatives and settings around the world. Many organizations adopt the NADA protocol as a tool for humanitarian aid and social justice. NADA has diverse leadership and membership, reflecting the people we serve.

Unfortunately, NADA has often met with fierce opposition from acupuncture organizations. In contrast, however, licensed acu- 
puncturists as individuals have been quite supportive and actually comprise $40 \%$ of the general NADA membership. The majority of NADA members are representative of the multidisciplinary healthcare mainstream, including biomedical, social service, psychotherapy, peer counseling, public health, substance misuse, criminal justice, and integrative treatment providers. Collectively and for decades the general NADA membership has led the way in demonstrating what informed integrated care looks like and in proving the many benefits that can accrue from adopting the principles of NADA-style care.

In this moment, we face both the collective, acute trauma of a pandemic that is affecting lives and livelihoods and the chronic trauma of systematic, structural racism and oppression. Our nation needs what NADA can contribute-group response to group trauma. NADA offers a wholistic approach to a mental health system unequipped to address the overwhelming despair that has brought us to epidemic levels of addiction, anxiety and depression. NADA stands behind utilizing our protocol for the empowerment of historically oppressed peoples, preferabl delivered by those same peoples.

People of color and other marginalized communities face unnaturally high levels of stress-exposure and multi-generational trauma that can predispose, precipitate, and perpetuate a host of short-term and long-term adverse, severe and too often deadly physical and mental health concerns. The denial of basic rights to equality as a United States citizen and inalienable rights as a human being is unconscionable. The right to healthcare is a critical part of this calculus. NADA protocol specifically is a safe and effective method that can help programs, providers, and patients to cope better with these ill effects. The NADA protocol is especially notable for its extremely low risk of adverse outcomes, which creates a potential benefit-to-risk ratio that is absolutely unmatched by any pharmaceutical or other somatic intervention currently available.

In closing, the authors emphasize that an analysis of the Lincoln experience can inform how best to respond to the social unrest that is now manifesting across the country and across color and socio-economic lines in support of Black and Brown lives. Coming full circle, explosive social unrest has returned to challenge us here in the US. The "Spirit of NADA" stands as a time-tested model for effectively addressing that challenge with the integrity and inclusiveness that it deserves.

The iconic concept of the "Barefoot Doctor" is one often held up as a model of unselfish service. NADA invites the local, state, and national acupuncture organizations to actively support the NADA mission and goals as a manifestation of that kind of service. The widespread use of the NADA protocol by non-LAc NADA-trained frontline, community-based Acupuncture Detoxification Specialists (ADSes) offers one of the very best hopes of sufficient, appropriate, culturally relevant, and on-going access to care. Even California's roughly 18,000 licensed acupuncturists could not begin to touch the need in that state. Furthermore, the widespread use of the NADA protocol by non-LAc providers in states with NADA-inclusive legislation supports the Traditional East Asian Medicine (TEAM) profession by spreading acupuncture awareness and goodwill. Broad-based support of NADA ADS inclusions in all 50 states can indeed be a win for all.

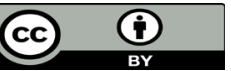

This work is licensed under Creative Commons Attribution 4.0 License

To Submit Your Article Click Here: Submit Article

DOI: $10.32474 /$ OAJCAM.2020.02.000143

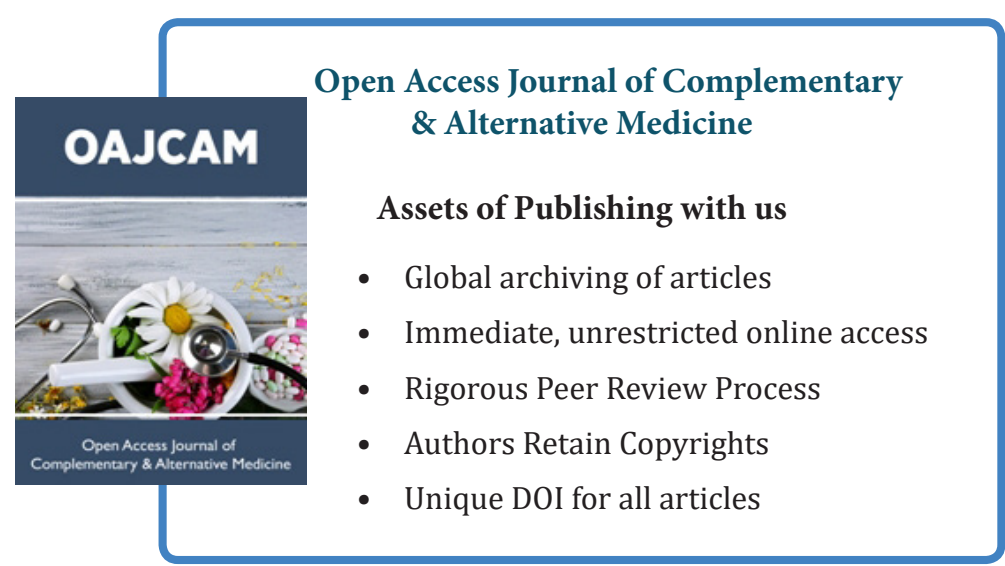

